Matthieu Durand-Hill ORCID iD: 0000-0001-6688-2892

\title{
Can Custom 3D Printed Implants Successfully Reconstruct Massive Acetabular Defects? a 3D-CT Assessment
}

Running title: Reconstructing Massive Acetabular Defects

Matthieu Durand-Hill ${ }^{1}$, Johann Henckel ${ }^{2}$, Anna Di Laura ${ }^{2}$, Alister J. Hart ${ }^{1,2}$

1. Institute of Orthopaedics and Musculoskeletal Science, University College London

2. Royal National Orthopaedic Hospital, Stanmore, United Kingdom

Author Contributions Statement: research design: AH, JH, MDH; data acquisition: $\mathrm{AH}, \mathrm{JH}, \mathrm{MDH}, \mathrm{ADL}$; data analysis: $\mathrm{AH}, \mathrm{JH}, \mathrm{MDH}, \mathrm{ADL}$ manuscript writing: $\mathrm{AH}, \mathrm{JH}$, MDH, ADL.

Corresponding Author: Matthieu Durand-Hill

Institute of Orthopaedics and Musculoskeletal Science (University College London), Royal National Orthopaedic Hospital, Brockley Hill, Stanmore, Middlesex, HA7 4LP, United Kingdom. Phone: +44 (0) 2089095825 Fax: $\quad$ +44 (0) 2089548560

Email: matthieu.durand-hill@nhs.net

Matthieu Durand-Hill: matthieu.durand-hill@nhs.net

Johann Henckel: j.henckel@ucl.ac.uk

Anna Di Laura: anna.laura.14@ucl.ac.uk

Alister J. Hart: a.hart@ucl.ac.uk

This article has been accepted for publication and undergone full peer review but has not been through the copyediting, typesetting, pagination and proofreading process, which may lead to differences between this version and the Version of Record. Please cite this article as doi: 10.1002/jor.24752.

This article is protected by copyright. All rights reserved. 


\begin{abstract}
We report on the accuracy, measured with 3D Computed Tomography (CT) postoperatively, in positioning custom three-dimensional (3D) printed titanium components in patients with large acetabular defects.
\end{abstract}

Twenty patients (13 Females and 7 Males) received custom-made acetabular implants between 2016 and 2018; mean age was 66 years $(S . D=11.6)$ and their mean BMI was 28 (S.D = 6.1). The median time to follow up was 25.5 months, range 12-40 months.

We describe a comparison method that uses the 3D models of CT-generated preoperative plans and the post-operative CT scans to quantify the discrepancy between planned and achieved component position. Our primary outcome measures were the 3D CT measured difference between planned and achieved component position in six degrees of freedom: Centre of Rotation (CoR), component rotation, Inclination (INC) \& Version (VER) of the cup. Our secondary outcome measures were: Oxford hip score, walking status and complication rate.

All components $(100 \%)$ were positioned within $10 \mathrm{~mm}$ of planned CoR (in the three planes). Eighteen (95\%) components were not rotated by more than $10^{\circ}$ compared to plan. Eleven $(58 \%)$ components were positioned within $5^{\circ}$ of planned cup angle (inclination and version). To date one complication has occurred, a periprosthetic fracture.

This is the largest study in which post-operative 3D-CT measurements and clinical outcomes of custom-made acetabular components have been assessed. Accurate pre-

This article is protected by copyright. All rights reserved. 
op planning and the adoption of custom 3D printed implants shows promising results in complex hip revision surgery.

Keywords: Paprosky acetabular defects; Revision Hip Surgery; Computed Tomography; Custom 3D Printed Implants; Image Analysis for component Orientation.

\section{Introduction}

The economic burden of revision total hip arthroplasty (THA) has increased over the last decade ${ }^{(1,2)}$. According to the UK National Joint Registry, a total of 8,589 revision procedures were performed in 2017 alone ${ }^{(3)}$. The increasing number of primaries being performed in younger patients, combined with an aging population, may explain the growing incidence of revision surgeries, as more patients outlive or wear out their components ${ }^{(4)}$.

Revision THA can be challenging even for the most experienced surgeon ${ }^{(5)}$. The revision surgeon has to manage bone stock loss, which increases with each subsequent procedure. Inaccurate classification of periacetabular bony defects results in difficult acetabular fixation intraoperatively ${ }^{(6)}$. The Paprosky classification system for periacetabular defects is widely recognised and provides a basis for implant selection ${ }^{(5)}$. Paprosky 3B defects are the most severe and are characterized by supporting bone loss greater than $60 \%$ and significant superior-medial migration of the hip centre of rotation $(\mathrm{CoR})^{(7,8)}$. Traditionally antiprotrusio cages, spanning the ischium and ilium, have been the preferred devices used for the management of massive acetabular defects ${ }^{(9)}$. However, their use is associated with high (29\%) rates of failure ${ }^{(10)}$.

This article is protected by copyright. All rights reserved. 
Advances in thin slice metal artefact reduction Computed Tomography (CT), image analysis and reconstruction, have allowed for computerised modelling of these defects. Additive manufacturing has enabled the accurate production of bespoke titanium implants with integral porosity providing a fairly new tool to manage massive acetabular defects in revision hip surgery ${ }^{(5,9,11-14)}$. Given the novelty of this technology, there is paucity of data reporting on the accuracy of executing the surgical plan, in other words, measurement of post-operative component orientation (12).

We aimed to better understand the accuracy in positioning custom-made acetabular component at revision THA in patients with massive acetabular defects. Our primary objective was to assess accuracy in delivering the surgical plan. Our secondary objective was to evaluate clinical and radiological outcomes.

\section{Methods}

\subsection{Study Design and Outcome Measures}

Between 2016 and 2018, twenty consecutive patients (13 Females and 7 Males) were a candidate for receiving a custom 3D printed acetabular cups, Lima ProMade ${ }^{\mathrm{TM}}$ (Lima Corporate, San Daniele del Friuli, Italy). All cases had radiographic evidence (CT/plain radiograph) of massive Paprosky type acetabular defects.

The level of evidence for this paper is II. Patient details were anonymised throughout the study. Approval was granted by the Institutional Review Board (Reg. Number SE16.021).

This article is protected by copyright. All rights reserved. 
We report a comparison method that uses the 3D models of a CT-generated preoperative plan and a post-operative CT to obtain the discrepancy in six degrees of freedom, Figure 1. Component design and pre-operative planning was undertaken with close collaboration between surgeons and engineers. Continued follow up (median 25.5 months, range 12-40) was performed to monitor clinical outcome. Oxford Hip scores (OHS) ${ }^{(15)}$, post-operative walking status and complications were recorded. Study design is showed in Figure 2.

The outcome measures were: 1) Planned vs achieved CoR (in three planes), 2) Component rotation, 3) Planned vs. achieved inclination and version cup angles (in relation to the anterior pelvic plane); 4) OHS, walking status and dislocation rate were also recorded.

\subsection{Pre-Operative Planning}

The patients underwent metal artefact reduction sequencing CT scanning of their whole pelvis. The manufacturer of the implants used commercially available software (Mimics 19.0, Materialise, Belgium) to segment and generate a virtual 3D reconstruction of the patient's bony pelvis. Data from CT scans was used for accurate assessment of the centre of rotation of the failed hip.

Designing the custom titanium implant involved the following key steps: 1) filling the defect with porous titanium, 2) assuring fixation with structural titanium and screw holes and 3) determining the optimal location of centre of rotation.

Once approved, the ProMade ${ }^{\mathrm{TM}}$ implants were produced using EBM additive manufacturing with regions of trabecular titanium to promote osteointegration ${ }^{(16,17)}$. Alongside the titanium implant, plastic models of the patient's pelvis, the custom

This article is protected by copyright. All rights reserved. 
implant and the drill guides are manufactured using 3D printing and sterilised for intraoperative use.

Close collaboration between surgeon and engineer aided the final design. All Preoperative plans were saved as (STereoLithography STL) files and were used to produce 3D printed plastic models. The 3D printed models allowed the surgeon to: appreciate the patient's unique pelvic defect, trial implant positioning and explain the nature of the proposed operation to patients, Figure 3.

\subsection{Intra-Operative Procedure}

All surgeries were conducted by one senior orthopaedic surgeon who was sometimes accompanied by another senior orthopaedic surgeon or senior vascular surgeon. The key steps in surgery were: an extensile posterior approach, involvement of a vascular surgeon was required in $20 \%$ of the cases; reaming of non-viable bone as per plan, trial with 3D printed plastic implant model and fixation of 3D printed titanium implant with screws and patient specific drill guides.

\subsection{Post-operative Analysis}

\section{Image Registration}

Post-operatively, all patients received a low dose CT scan. Data from the CT scan was saved as a Digital Imaging and Communications in Medicine (DICOM) file. A relative comparison between planned and achieved component orientation and positions was carried out using Simpleware ${ }^{\mathrm{TM}}$ ScanIP (Version 2018.12; Synopsys, Inc., Mountain View, USA).

To generate 3D models of the patients' post-operative anatomy, each patient's DICOM series was imported into ScanIP. Following importation into the 3D This article is protected by copyright. All rights reserved. 
software, a threshold-based extraction method was performed to select two meshes: one of the pelvis and the other of the implanted 3D printed component ${ }^{(18)}$. Each mesh was subsequently saved as an STL file.

The STL files of the: Pre-operative plan, Post-operative pelvis and Post-operative component were all imported into a single ScanIP file for each patient. Using ScanIP the Post-operative component and pelvis were paired, so that their relative positions/orientations remained constant. Landmark registration was used to align the post-operative pelvis and pre-operative plan. The landmark registration works by rigidly translating the two objects to find positions in which all corresponding landmarks selected, are as close as possible.

Landmarks used for alignment were those of the anterior pelvic plane (Left and Right Anterior Superior Iliac Spines (ASIS) and Left and Right pubic tubercles), the Right and left Posterior Superior Iliac Spines (PSIS) and provided these were not obscured by metal artefact the ischial spines. Alignment was subsequently checked using a onesided Hausdorff distance between the post-operative pelvis and Pre-operative plan within MeshLab (Pisa, Italy) ${ }^{(18)}$.

\section{Planned Vs Achieved CoR}

The co-registered (planned and post-operative) STL files were opened within ScanIP. The local co-ordinate system was defined so that: the $\mathrm{X}$-axis corresponded to a line passing between the left and right ASIS (Medial-Lateral (ML) axis); the Y axis corresponded to a line passing between the midpoint of a line between the left and right pubic tubercle and the midpoint of a line passing between the left and right ASIS (Inferior-Superior (IS) axis).

This article is protected by copyright. All rights reserved. 
This resulted in the $\mathrm{Z}$ axis being the Anterior-Posterior (AP) axis, assuming 0 degrees of pelvic tilt. A sphere matching technique was used to determine the centre of rotation of the components ${ }^{(18,19)}$. The co-ordinates of the centre of rotation for the planned and achieved centre rotation were recorded and compared in all axes. The limit for translation of CoR, beyond which components were labelled malpositioned, was $10 \mathrm{~mm}$ in any plane.

\section{Planned Vs Achieved Component rotation}

The co-ordinate system used to measure the CoR was utilised to determine component rotation. Using this co-ordinate system: inclination is rotation about the $\mathrm{Z}$ axis, version is rotation about the $\mathrm{Y}$ axis and component rotation is rotation about the $\mathrm{X}$ axis. Zero degrees of rotation was defined as the point at which a line, from the component CoR to the point on the component most distal to the CoR, is in a Y plane parallel to the APP. Degrees of rotation were then measured clockwise from this position. The limit for component rotation, beyond which components were labelled malpositioned, was $10^{\circ}$ of rotation ${ }^{(20)}$.

\section{Planned Vs. Achieved Inclination and Version Cup Angles}

Planned and achieved inclination (INC) and version (VER) angles were calculated within the ScanIP software. The co-ordinates of ten points around the acetabular components' rim were used to define the cup plane. The orientation of the cup plane was then compared to the Anterior Pelvic Plane (APP); a standard frame of reference defined using the co-ordinates of the right and left anterior superior iliac spines (ASIS) and one pubic tubercle, Figure 4.

This article is protected by copyright. All rights reserved. 
This process was performed for the planned and implanted component of each case. The limit for cup angle, beyond which components were labelled malpositioned, was $5^{\circ}$ from planned position.

\section{Clinical outcome}

Follow up of patients was performed by senior authors to monitor for complications. Post-operative walking status and oxford hip scores ${ }^{(15)}$ were recorded during latest follow up (12 to 40 months).

\section{Statistical analysis}

Statistical analysis was performed using SPSS (IBM Corp. Released 2012. IBM SPSS Statistics for Windows, Version 24.0. Armonk, NY: IBM Corp.). All data, apart from follow up length, was determined to be parametric using Qauntile-Quantile plots. One outlier (Case 3) was removed from statistical analysis. Pearson's test was used to determine correlations between CT measurement data (difference in $\mathrm{CoR}$, component rotation, cup INC and VER) and BMI, defect volume, the presence of discontinuity and two-stage procedure. The threshold for statistical significance was 0.05.

\section{Results}

Patients' characteristics are shown in Table 1. Models of the pre-operative pelvic defect are illustrated in Figure 5. Mean age was 66 years $(S . D=11.6)$ and their mean BMI was $28($ S.D = 6.1). Median follow up during this study was 25.5 months (IQR 17-33).

This article is protected by copyright. All rights reserved. 


\subsection{Radiographic outcome}

All components $(100 \%)$ were positioned within $10 \mathrm{~mm}$ of planned CoR (in the three planes). Eighteen (95\%) components were not rotated by more than $10^{\circ}$ compared to plan. Eleven $(58 \%)$ components were positioned within $5^{\circ}$ of planned cup angle (inclination and version), Table 2. To date one complication has occurred (Case 3), a periprosthetic fracture. Calculation of postoperative component positioning was based upon the CT obtained post fracture. As the post-operative CT did not represent intraoperative component positioning, this case was removed from data analysis.

The mean difference, between planned and achieved, CoR was $-0.1 \mathrm{~mm}(95 \% \mathrm{CI}-8.7$, 8.6) in the: AP plane, $-1.4 \mathrm{~mm}(95 \% \mathrm{CI}-7.6,4.8)$ in the IS plane and $0.1 \mathrm{~mm}(95 \% \mathrm{CI}$ -9.4 9.5) in the LM plane.

The mean deviation of component rotation from planned was $2.2^{\circ}(-6.4,10.8)$.

Planned INC had a mean of $40.3^{\circ}(95 \%$ CI $29.2,51.5)$ and $40.5^{\circ}(95 \%$ CI $26.6,54.4)$ post-operatively; the difference between the planned and post-operative INC was $0.2^{\circ}$ (95\% CI -10.2 to 10.7$)$. The mean planned VER was $14.2^{\circ}$ (95\% CI -3.5, 31.9), VER post-operatively was $17.0^{\circ}(95 \% \mathrm{CI}-0.7,33.3)$ with a mean difference between planned and post-operative VER of $2.8^{\circ}(95 \%$ CI -10.5, 16.1).

3D models of the difference between planned and achieved implant orientation are shown in figure 6 (case 20) and figure 7 (whole cohort).

\subsection{Clinical outcome}

Duration of post-operative follow up and post-operative walking status are shown in

Table 3. Mean oxford hip score at latest follow up was 32.4 (S.D 10.4). Two patients This article is protected by copyright. All rights reserved. 
had an oxford hip score less than 20 (Cases 1 and 9), case 1 is reporting contralateral hip symptoms.

Case 3 had a peri-operative complication, a comminuted fracture of the iliac crest and failure of fixation inferiorly. The component was considered stable and no fracture was suspected intraoperatively. In addition, no fracture was apparent on immediate postoperative imaging (plain radiographs). Early ambulation occurred postoperatively, during which the patient suspected that the component had migrated. Subsequent imaging (CT and plain radiograph) revealed the fracture.

No dislocations have occurred to date.

\subsection{Statistical correlation}

No significant correlation ( $\mathrm{p}>0.05)$ was found between CT measurement data (difference in CoR, component rotation, cup INC and VER) and BMI, defect volume, the presence of discontinuity or two-stage procedure.

\section{Discussion}

We have presented our method to assess plan compliance immediately postoperatively in patients with massive acetabular defects. We report on the accuracy, measured with 3D-CT post-operatively, in positioning custom 3D-printed titanium components and detail our technique to assess plan compliance in six degrees of freedom, Figure 6.

All components $(100 \%)$ were positioned within $10 \mathrm{~mm}$ of planned $\mathrm{CoR}$ (in the three planes). Eighteen (95\%) components were not rotated by more than $10^{\circ}$ compared to plan. Eleven $(58 \%)$ components were positioned within $5^{\circ}$ of planned cup angle

This article is protected by copyright. All rights reserved. 
(inclination and version). To date one complication has occurred (Case 3), a periprosthetic fracture.

In Case 3, a comminuted fracture of the iliac crest occurred. Reports of periprosthetic fractures in the treatment of massive acetabular defects are expected ${ }^{(9,12)}$. The poor bone quality combined with the massive osteolytic defects found explains the risk of periprosthetic fractures, in this patient group ${ }^{(12,21)}$.

Traditionally the positioning of the acetabular component in hip arthroplasty has been defined in terms of inclination and version angles ${ }^{(22)}$. These terms describe the orientation of the acetabular axis ${ }^{(23)}$ and assuming that the component is symmetrical about this axis, they provide a full account of component placement, when combined with the centre of rotation (CoR). However, 3D printed triflange components are not normally symmetrical about the acetabular axis; as such, positioning must be described in all six degrees of freedom, Figure 1.

Within the literature there is no clear consensus on the accuracy with which the planned CoR can be achieved, when using custom made components to treat severe Paprosky defects. A limit of $10 \mathrm{~mm}$ of translation in any plane was selected for the CoR; beyond this the component was deemed to be malpositioned. These limits were determined on the basis of consensus between the authors and the severity of bone defects, Figure 5. Our results indicate that $>95 \%$ of custom-made components would be placed within these limits.

CT data is one potential source of translational error when placing custom made components in patients with massive acetabular defects. Difficulty following the preoperative plan, and press fitting the custom component, arose when intraoperative

This article is protected by copyright. All rights reserved. 
defect topography differed from that seen on CT. Errors in CT most often occur due to: metal artefact (both from contralateral components and the component to be revised) and poor selection of CT acquisition parameters (high slice thickness, high pitch, low voltage or milliamps) ${ }^{(29,30)}$.

In an effort to reduce metal artefact five cases were performed as a two-step procedure. During which imaging was obtained after metal work was removed. We found no difference in accuracy between cases performed as one or two-stage procedures. However, we appreciate the limited number of two stage procedures included.

Component rotation is not usually measured during the post-operative assessment of component placement ${ }^{(31,32)}$. In tri-flanged components it affects the position of screw holes and consequently can affect fixation. The clinical significance of small degrees of component rotation is unknown and is likely to depend upon component design and patient anatomy. To date the component with $>10^{\circ}$ of component rotation remains stable.

Lewinnek, Lewis (33) proposed safe zones for anteversion and inclination of $15^{\circ} \pm$ $10^{\circ}$ and $40^{\circ} \pm 10^{\circ}$ respectively. Outside of which components were believed to be of increased risk of dislocation.

Positioning acetabular components within Lewinnek's safe zones in patients with Paprosky type 3 defects is notoriously challenging. In Choi et al's ${ }^{(34)}$ series of paprosky 3B patients, freehand positioning of the acetabular component within Lewinnek's safe zone occurred in only $56 \%$ of patients. Within our study fourteen

This article is protected by copyright. All rights reserved. 
cases $(74 \%)$ were positioned within Lewinnek's proposed safe zone. These results are comparable with previous series ${ }^{(12,34)}$.

It is important to note that within our study the aim of planning was not to achieve acetabular orientation within Lewinnek's safe zone. A meta-analysis by Seagrave, Troelsen (35) concluded that Lewinnek's safe zones were not clinically justified. Instead they concluded that individualised safe zones, accounting for pelvic tilt, were required. This is especially true in patients who have large acetabular defects ${ }^{(12)}$. However, there is currently no clear consensus on a method to calculate these individual safe zones.

Stability was checked on the operative table and acetabular face changers were occasionally recruited to optimise the acetetabular orientation. And with severe muscular pathology, the lead surgeon opted for the dual mobility bearing.

We found no significant correlation between CT measurement data (difference in CoR, component rotation, cup INC and VER) and BMI, defect volume or the presence of discontinuity. However, interpretation is limited given the low sample size. BMI has previously been demonstrated as a risk factor for acetabular component malpositioning ${ }^{(36)}$. With regards to defect volume, the conscious of the authors is that other characteristics of the defect, e.g. shape, are more likely to influence accuracy of component positioning.

Direct comparison between studies is of limited value as there is a wide spectrum of acetabular defects, Figure 5. Furthermore, reports of results with these components are sparse with only a limited number of published cases detailing post-operative positioning in six degrees of freedom. Only one other study, to the authors

This article is protected by copyright. All rights reserved. 
knowledge, has assessed component placement in six degrees of freedom. Baauw et al. ${ }^{(12)}$ assessed 16 patients fitted with the aMace acetabular revision system (Mobelife, Leuven, Belgium). The type of acetabular defects present in their cohort was of Paprosky 3, with inclusion of both type A and B. In addition, there was no report of cases with discontinuity. The radiological results and complication rates that the authors reported are comparable to those found in this study.

\section{Conclusion}

There is no consensus regarding the best option for reconstructing massive acetabular defects. New custom-made components have been proposed as a solution to treat patients with these defects. However, reports on the accuracy and clinical outcome in the literature are sparse. Malpositioning in the medial-lateral plane is thought to be most clinically relevant ${ }^{(12)}$. In our study, the discrepancy between planned and achieved CoR in the LM plane was greater than $10 \mathrm{~mm}$ in none of the cases.

We have presented our method to assess plan compliance immediately postoperatively in patients with massive acetabular defects. Accurate pre-op planning and the adoption of custom 3D printed implants are a viable option in the reconstruction of massive Paprosky type acetabular defects showing promising short- and mediumterm results in complex hip revision surgery.

\section{Acknowledgements}

This research study was funded by The Maurice Hatter Foundation, the RNOH Charity, the Rosetrees Trust and the Stoneygate Trust and supported by researchers at the National Institute for Health Research University College London Hospitals

This article is protected by copyright. All rights reserved. 
Biomedical Research Centre. Software licenses were provided by Synopsys Simpleware.

\section{Conflict of interest}

Authors $\mathrm{AH}$ and $\mathrm{JH}$ have received institutional grant funding from Lima Corporate and not for this project. The remaining authors have no potential conflicts of interest to report.

\section{References}

1. Ong KL, Mowat FS, Chan N, Lau E, Halpern MT, Kurtz SM. Economic burden of revision hip and knee arthroplasty in Medicare enrollees. Clin Orthop Relat Res. 2006;446:22-8.

2. Weber M, Renkawitz T, Voellner F, Craiovan B, Greimel F, Worlicek M, et al. Revision Surgery in Total Joint Replacement Is Cost-Intensive. Biomed Res Int. 2018;2018:8987104.

3. The National Joint Register. 15th Annual report2018.

4. Bayliss LE, Culliford D, Monk AP, Glyn-Jones S, Prieto-Alhambra D, Judge A, et al. The effect of patient age at intervention on risk of implant revision after total replacement of the hip or knee: a population-based cohort study. Lancet. 2017;389(10077):1424-30.

5. Aprato A, Giachino M, Bedino P, Mellano D, Piana R, Masse A. Management of Paprosky type three $B$ acetabular defects by custom-made components: early results. Int Orthop. 2019;43(1):117-22.

6. Paprosky WG, Perona PG, Lawrence JM. Acetabular defect classification and surgical reconstruction in revision arthroplasty. A 6-year follow-up evaluation. J Arthroplasty. 1994;9(1):33-44.

7. Sheth NP, Nelson CL, Springer BD, Fehring TK, Paprosky WG. Acetabular bone loss in revision total hip arthroplasty: evaluation and management. J Am Acad Orthop Surg. 2013;21(3):128-39.

8. Telleria JJ, Gee AO. Classifications in brief: Paprosky classification of acetabular bone loss. Clin Orthop Relat Res. 2013;471(11):3725-30.

9. Barlow BT, Oi KK, Lee YY, Carli AV, Choi DS, Bostrom MP. Outcomes of Custom Flange Acetabular Components in Revision Total Hip Arthroplasty and Predictors of Failure. J Arthroplasty. 2016;31(5):1057-64.

This article is protected by copyright. All rights reserved. 
10. Berry DJ, Muller ME. Revision arthroplasty using an anti-protrusio cage for massive acetabular bone deficiency. J Bone Joint Surg Br. 1992;74(5):711-5.

11. Ahmad AQ, Schwarzkopf R. Clinical evaluation and surgical options in acetabular reconstruction: A literature review. J Orthop. 2015;12(Suppl 2):S238-43.

12. Baauw M, van Hellemondt GG, van Hooff ML, Spruit M. The accuracy of positioning of a custom-made implant within a large acetabular defect at revision arthroplasty of the hip. Bone Joint J. 2015;97-B(6):780-5.

13. Citak M, Kochsiek L, Gehrke T, Haasper C, Suero EM, Mau H. Preliminary results of a 3D-printed acetabular component in the management of extensive defects. Hip Int. 2018;28(3):266-71.

14. Myncke I, van Schaik D, Scheerlinck T. Custom-made triflanged acetabular components in the treatment of major acetabular defects. Short-term results and clinical experience. Acta Orthop Belg. 2017;83(3):341-50.

15. Dawson J, Fitzpatrick R, Carr A, Murray D. Questionnaire on the perceptions of patients about total hip replacement. J Bone Joint Surg Br. 1996;78(2):185-90.

16. Asti A, Gastaldi G, Dorati R, Saino E, Conti B, Visai L, et al. Stem cells grown in osteogenic medium on PLGA, PLGA/HA, and titanium scaffolds for surgical applications. Bioinorganic chemistry and applications. 2010;2010.

17. Marin E, Fusi S, Pressacco M, Paussa L, Fedrizzi L. Characterization of cellular solids in Ti6Al4V for orthopaedic implant applications: Trabecular titanium. Journal of the mechanical behavior of biomedical materials. 2010;3(5):373-81.

18. Durand-Hill M, Henckel J, Satchithananda K, Sabah S, Hua J, Hothi H, et al. Calculating the hip center of rotation using contralateral pelvic anatomy. J Orthop Res. 2016;34(6):1077-83.

19. Ehrig RM, Taylor WR, Duda GN, Heller MO. A survey of formal methods for determining the centre of rotation of ball joints. J Biomech. 2006;39(15):2798-809.

20. Baauw M, van Hellemondt GG, Spruit M. A custom-made acetabular implant for Paprosky type 3 defects. Orthopedics. 2017;40(1):e195-e8.

21. Davidson D, Pike J, Garbuz D, Duncan CP, Masri BA. Intraoperative periprosthetic fractures during total hip arthroplasty. Evaluation and management. J Bone Joint Surg Am. 2008;90(9):2000-12.

22. Murray DW. The definition and measurement of acetabular orientation. J Bone Joint Surg Br. 1993;75(2):228-32.

23. Wan Z, Malik A, Jaramaz B, Chao L, Dorr LD. Imaging and navigation measurement of acetabular component position in THA. Clin Orthop Relat Res. 2009;467(1):32-42.

This article is protected by copyright. All rights reserved. 
24. Lengsfeld M, Bassaly A, Boudriot U, Pressel T, Griss P. Size and direction of hip joint forces associated with various positions of the acetabulum. J Arthroplasty. 2000;15(3):314-20.

25. Bicanic G, Delimar D, Delimar M, Pecina M. Influence of the acetabular cup position on hip load during arthroplasty in hip dysplasia. Int Orthop. 2009;33(2):397402.

26. Sariali E, Klouche S, Mamoudy P. Investigation into three dimensional hip anatomy in anterior dislocation after THA. Influence of the position of the hip rotation centre. Clin Biomech (Bristol, Avon). 2012;27(6):562-7.

27. Stewart TD, Tipper JL, Insley G, Streicher RM, Ingham E, Fisher J. Severe wear and fracture of zirconia heads against alumina inserts in hip simulator studies with microseparation. J Arthroplasty. 2003;18(6):726-34.

28. Bonnin MP, Archbold PH, Basiglini L, Fessy MH, Beverland DE. Do we medialise the hip centre of rotation in total hip arthroplasty? Influence of acetabular offset and surgical technique. Hip Int. 2012;22(4):371-8.

29. Barrett JF, Keat N. Artifacts in CT: recognition and avoidance. Radiographics. 2004;24(6):1679-91.

30. J. G. Radiology Physics: A Handbook for Teachers and Students: International Atomic Energy Agency; 2014.

31. Dennis DA. Management of massive acetabular defects in revision total hip arthroplasty. J Arthroplasty. 2003;18(3 Suppl 1):121-5.

32. Joshi AB, Lee J, Christensen C. Results for a custom acetabular component for acetabular deficiency. J Arthroplasty. 2002;17(5):643-8.

33. Lewinnek GE, Lewis JL, Tarr R, Compere CL, Zimmerman JR. Dislocations after total hip-replacement arthroplasties. J Bone Joint Surg Am. 1978;60(2):217-20.

34. Choi HR, Anderson D, Foster S, Beal M, Lee JA, Barr C, et al. Acetabular cup positioning in revision total hip arthroplasty with Paprosky type III acetabular defects: Martell radiographic analysis. Int Orthop. 2013;37(10):1905-10.

35. Seagrave KG, Troelsen A, Malchau H, Husted H, Gromov K. Acetabular cup position and risk of dislocation in primary total hip arthroplasty. Acta Orthop. 2017;88(1):10-7.

36. Callanan $M C$, Jarrett $B$, Bragdon CR, Zurakowski D, Rubash HE, Freiberg AA, et al. The John Charnley Award: risk factors for cup malpositioning: quality improvement through a joint registry at a tertiary hospital. Clin Orthop Relat Res. 2011;469(2):319-29.

This article is protected by copyright. All rights reserved. 


\section{Figures}

Figure 1. The six degrees of freedom of a tri-flanged acetabular component. A) Translation of the CoR can occur in a Superior-Inferior (SI), Anterior-Posterior (AP) and Lateral-Medial (LM) direction. B) Rotation about three perpendicular axes results in changes in Inclination, Version and Component rotation.
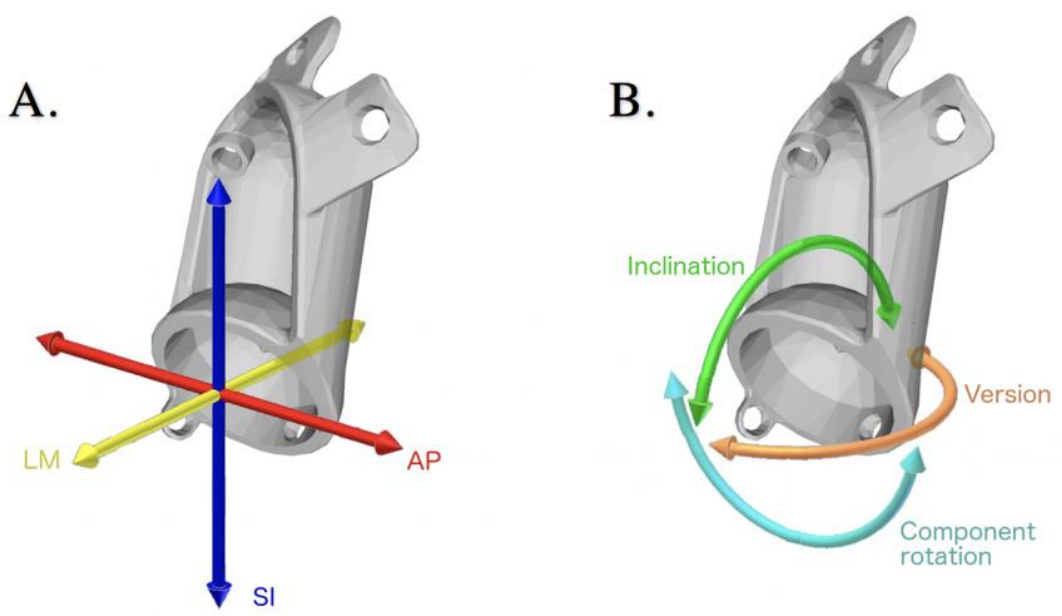

Figure 2: Flow chart of the study design.

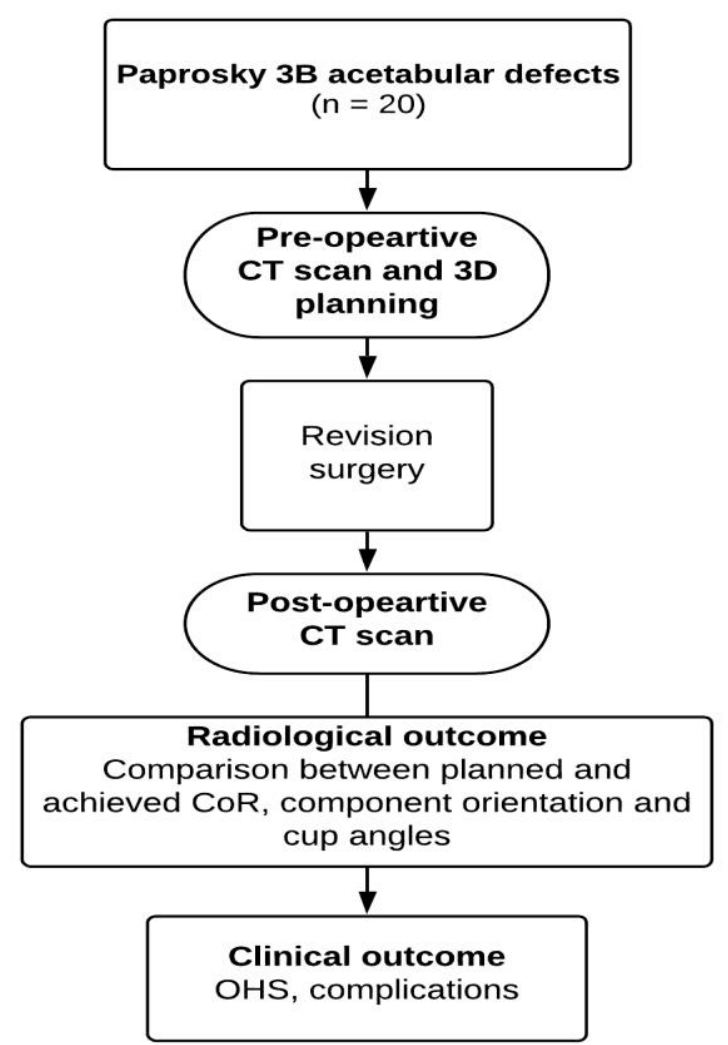

This article is protected by copyright. All rights reserved. 
Figure 3: (A) Pre-operative AP pelvic radiograph, (B) 3D model of pelvic defect and (C) surgical plan for case 20 .

\section{Case 20}

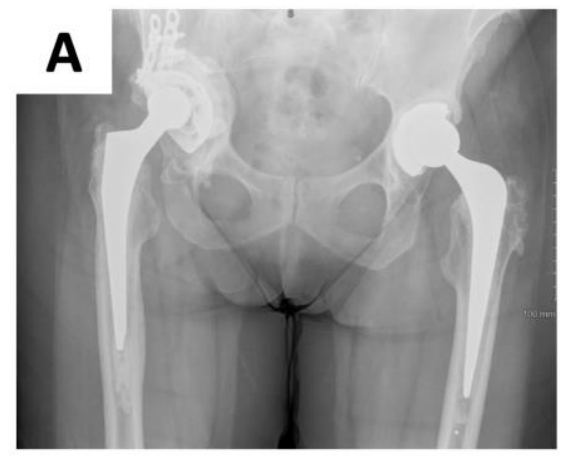

B

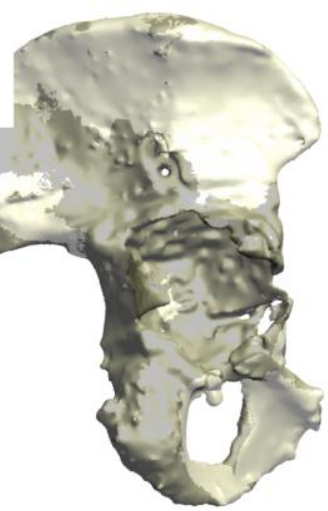

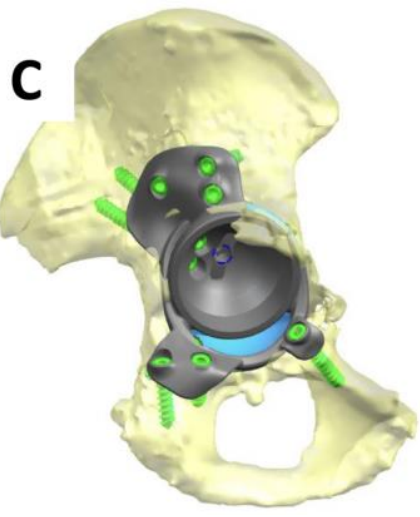

Figure 4: Ten points (D-M) were used to create a cup plane which was correlated to the APP (points A-C) to determine cup inclination and version angles.
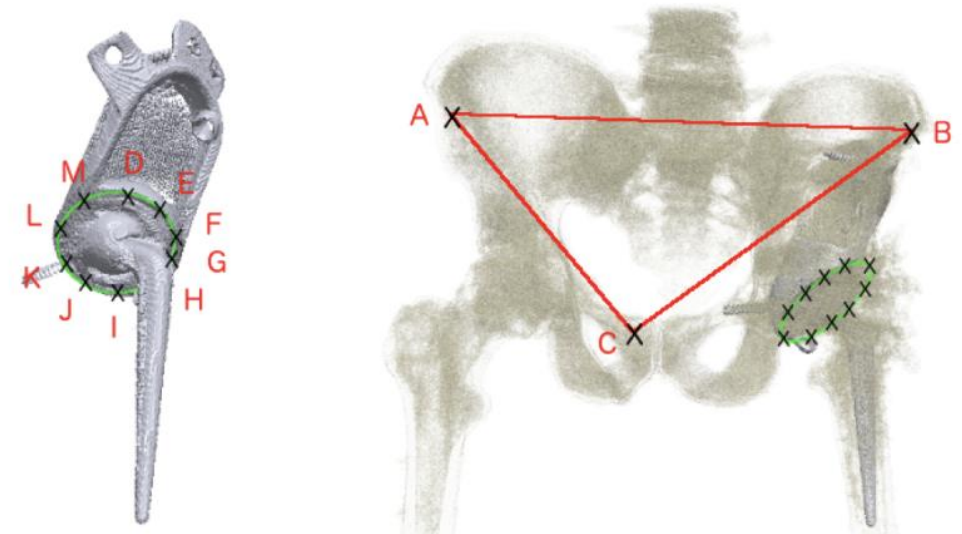

This article is protected by copyright. All rights reserved. 
Figure 5: Anterior-posterior (top) and lateral (bottom) views of 3D models generated from pre-operative CT scans illustrating the defect present in each case.

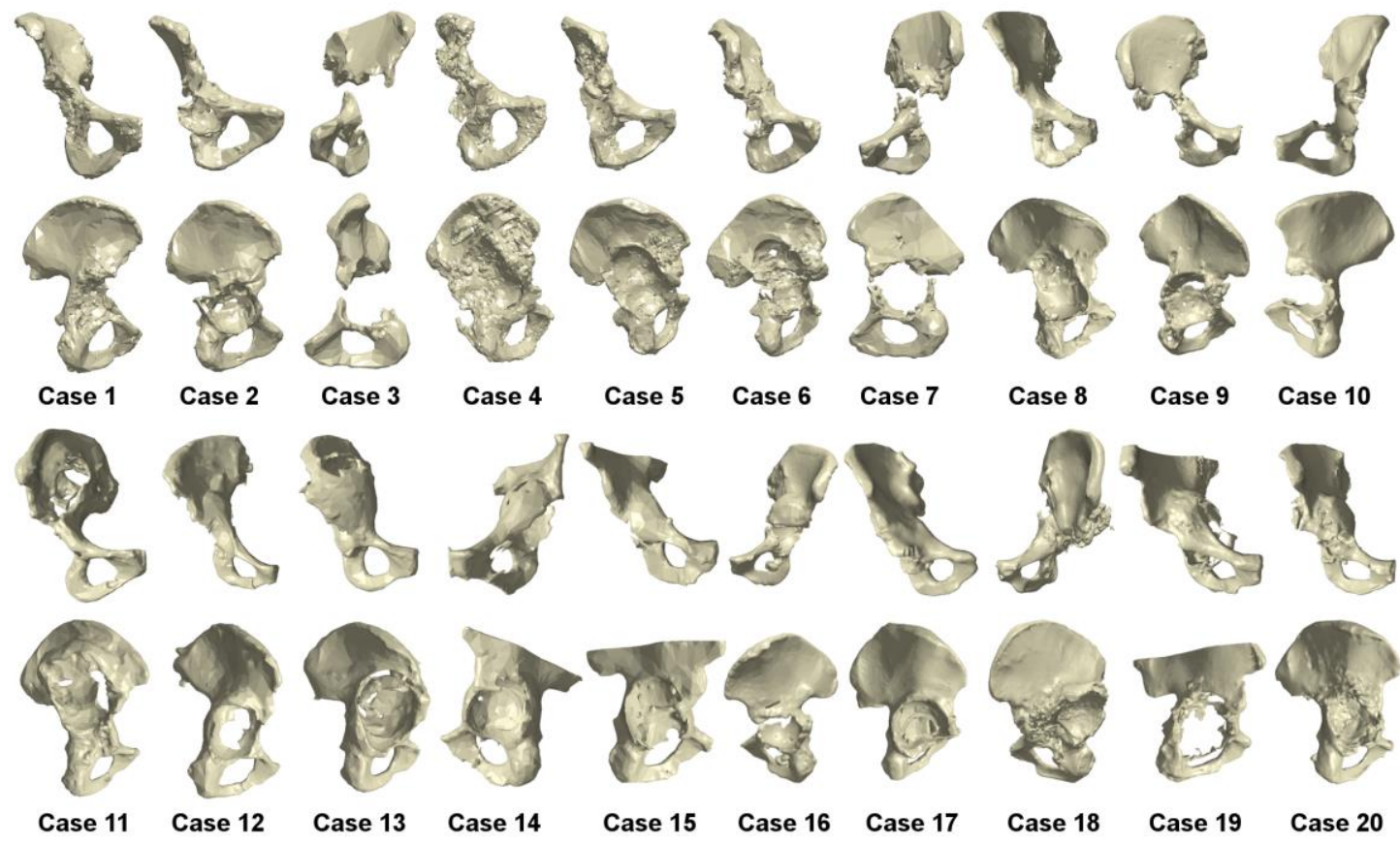

Figure 6: (A) AP and (B) lateral views of pre (green) and post-operative (blue) components and $(\mathbf{C})$ post-operative EOS imaging showing restoration of leg length.
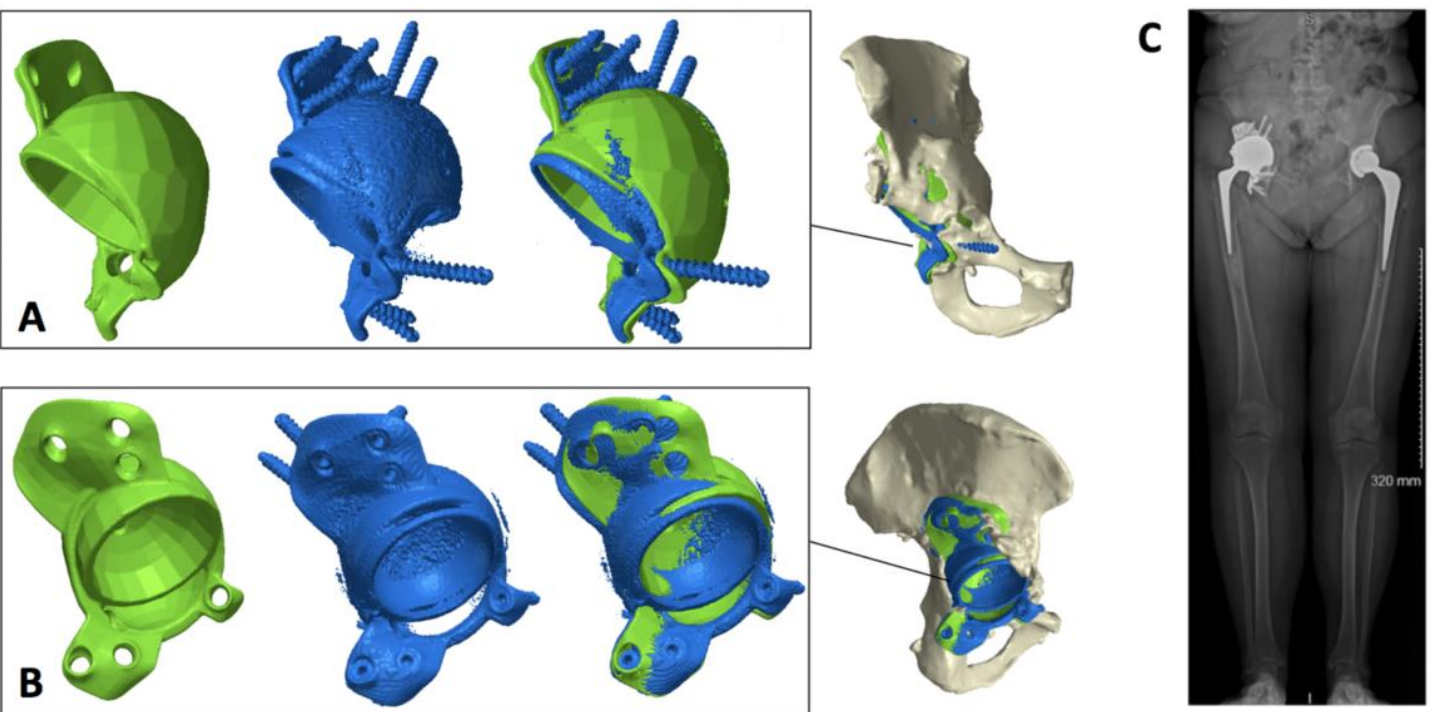

This article is protected by copyright. All rights reserved. 
Figure 7: 3D models of the cases, showing the planned position of the component (Green) and the post-operative location of the component (Blue). Component position is overlaid onto a model of the pelvis generated from the Pre-operative CT scan.

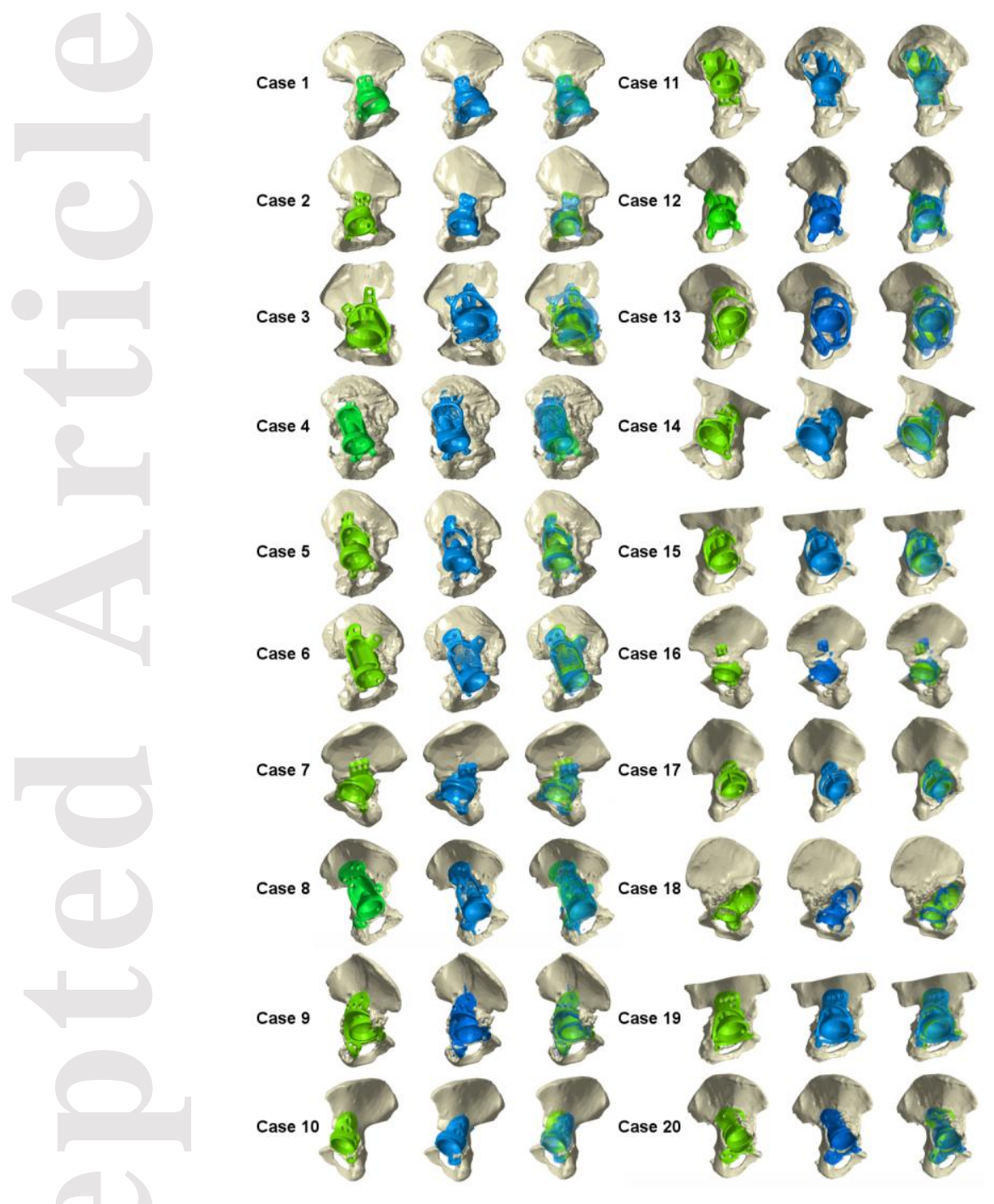

This article is protected by copyright. All rights reserved. 


\section{Tables}

Table 1. Patient characteristics

\begin{tabular}{|c|c|c|c|c|c|c|}
\hline Case & Age & BMI & Discontinuity & Op \#* & Mobility & Reason for revision \\
\hline 1 & 76 & 32 & No & 4 & Wheelchair & Failed MoM implant, loosening + infection \\
\hline 2 & 69 & 30 & Yes & 4 & Frame & $\begin{array}{l}\text { Dislocated revision right THR with a } \\
\text { constrained liner. Periprosthetic type C } \\
\text { fracture, managed by open reduction internal } \\
\text { fixation with distal femoral locking plate }\end{array}$ \\
\hline 3 & 78 & 26 & Yes & 4 & Frame & $\begin{array}{l}\text { Failed revision with medial migration of } \\
\text { socket }\end{array}$ \\
\hline 4 & 78 & 31 & No & 3 & 2 crutches & $\begin{array}{l}\text { Massive acetabular defect and loose hip } \\
\text { replacement and high CRP with negative } \\
\text { aspirate }\end{array}$ \\
\hline 5 & 61 & 22 & No & 2 & Frame & $\begin{array}{l}\text { Loose right THR with massive acetabular } \\
\text { bony defect }\end{array}$ \\
\hline 6 & 63 & 25 & No & 3 & Crutches & Loosening of revision hip arthroplasty \\
\hline 7 & 49 & 32 & Yes & 3 & 2 crutches & $\begin{array}{l}\text { Pelvic discontinuity following revision left } \\
\text { THR }\end{array}$ \\
\hline 8 & 90 & 23 & No & 3 & Trolley & Failure of revision right THR \\
\hline 9 & 71 & 30 & Yes & 3 & Frame & Infection and pelvic discontinuity \\
\hline 10 & 50 & 23 & No & 2 & None & $\begin{array}{l}\text { MoM hip resurfacing with high metal ions } \\
\text { levels and bone and soft tissue damage }\end{array}$ \\
\hline 11 & 57 & 29 & No & 3 & None & $\begin{array}{l}\text { Failure of MoP hip replacement with superior } \\
\text { migration of the hip }\end{array}$ \\
\hline 12 & 87 & 23 & No & 3 & Wheelchair & Failure of revision right THR \\
\hline
\end{tabular}

This article is protected by copyright. All rights reserved. 


\begin{tabular}{|c|c|c|c|c|c|c|}
\hline 13 & 63 & 48 & No & 3 & Wheelchair & Failed replacement with acetabular migration \\
\hline 14 & 56 & 37 & No & Multi† & 2 Crutches & Loose left long stem, loose acetabulum \\
\hline 15 & 62 & 26 & No & 2 & 2 Crutches & $\begin{array}{l}\text { Loose R Acetabulum MoP replacement with } \\
\text { subluxation }\end{array}$ \\
\hline 16 & 73 & 27 & No & 3 & 2 Crutches & $\begin{array}{l}\text { Failed MoP L hip with superior migration of } \\
\text { cup and stem, pelvic discontinuity. }\end{array}$ \\
\hline 17 & 53 & 26 & No & 1 & 2 Crutches & $\begin{array}{l}\text { Severe joint degradation, Presence of massive } \\
\text { fractured bone protrusion below acetabulum. }\end{array}$ \\
\hline 18 & 56 & 26 & No & 1 & None & $\begin{array}{l}\text { Hip Osteoarthritis secondary to acetabular } \\
\text { fracture }\end{array}$ \\
\hline 19 & 70 & 22 & No & 2 & 2 Crutches & Failure of revision right THR \\
\hline 20 & 70 & 30 & No & 5 & Wheelchair & Loosening and infection \\
\hline
\end{tabular}

* Op \#, total number of hip replacements including one in study

† Multi, no data on total number of hip replacements available greater than 2 known

Table 2. Centre of Rotation (COR) Rotation, Inclination and Version expressed as differences from the planned values

\begin{tabular}{|c|c|c|c|c|c|c|c|}
\hline \multirow{2}{*}{ Case } & \multicolumn{4}{|c|}{ CoR (mm) } & \multirow[t]{2}{*}{ Rotation clockwise $\left({ }^{\circ}\right)$} & \multirow{2}{*}{$\begin{array}{l}\text { Cup angles } \\
\text { Inc }\left(^{\circ}\right)\end{array}$} & \multirow{2}{*}{$\operatorname{Ver}\left({ }^{\circ}\right)$} \\
\hline & LM & IS & AP & Sum & & & \\
\hline 1 & -5 & -4 & 1 & 6 & 2 & -4 & 12 \\
\hline 2 & 3 & 0 & 3 & 4 & 7 & -2 & -5 \\
\hline $3^{*}$ & -10 & 19 & 5 & 22 & 10 & 12 & -13 \\
\hline 4 & 3 & 2 & 9 & 10 & -3 & -8 & 3 \\
\hline
\end{tabular}

This article is protected by copyright. All rights reserved. 


\begin{tabular}{|c|c|c|c|c|c|c|c|}
\hline 5 & 4 & -3 & -6 & 8 & 0 & -4 & 1 \\
\hline 6 & -4 & -2 & -3 & 5 & 0 & 2 & 19 \\
\hline 7 & 2 & -2 & 3 & 4 & 15 & 3 & 2 \\
\hline 8 & -9 & 0 & -5 & 10 & -2 & -5 & 2 \\
\hline 9 & 3 & 2 & 2 & 4 & 0 & 4 & 1 \\
\hline 10 & 0 & -2 & 0 & 2 & 10 & -3 & 0 \\
\hline 11 & -5 & -6 & 0 & 8 & 1 & 4 & -1 \\
\hline 12 & 0 & -6 & -2 & 6 & 1 & 1 & 5 \\
\hline 13 & -9 & -4 & -1 & 10 & 0 & -11 & 6 \\
\hline 14 & 1 & -4 & -4 & 6 & 0 & 0 & 0 \\
\hline 15 & 4 & -5 & 4 & 8 & 4 & 5 & 8 \\
\hline 16 & 2 & -2 & 3 & 4 & 7 & 10 & 11 \\
\hline 17 & -3 & 0 & -7 & 8 & 2 & 6 & 3 \\
\hline 18 & 4 & 6 & -6 & 9 & 0 & -3 & -2 \\
\hline 19 & 10 & 1 & 5 & 11 & 1 & 3 & -10 \\
\hline 20 & 0 & 2 & 3 & 4 & 1 & 5 & -2 \\
\hline
\end{tabular}

Discrepancies: $>10 \mathrm{~mm}$ for centre of rotation $(\mathrm{COR}),>10^{\circ}$ for rotation and $>5^{\circ}$ for cup angles between planned and post-operative positions are marked in bold. AP, anteroposterior; LM, lateromedial; SI, Superoinferior; Inc, Inclination; Ver, Version. Sum is the distance in $\mathrm{mm}$ between the two COR in three-dimensions.

* Imaging for case 3 was obtained after a peri-prosthetic fracture, results therefore do not inform on the component position achieved intraoperatively.

This article is protected by copyright. All rights reserved. 
Table 3. Post-operative walking status

\begin{tabular}{|c|c|c|c|}
\hline Case & F/U Month* & Walking status & Complication to date \\
\hline 1 & 33 & $\begin{array}{l}2 \text { crutches indoor, wheelchair } \\
\text { outside }\end{array}$ & Nil \\
\hline 2 & 33 & 1 crutch & Nil \\
\hline 3 & 27 & Wheelchair & Periprosthetic fracture, required revision \\
\hline 4 & 36 & Independent & Nil \\
\hline 5 & 40 & Unilateral walking stick & Nil \\
\hline 6 & 38 & Independent & Nil \\
\hline 7 & 35 & Unilateral walking stick & Nil \\
\hline 8 & 14 & Unilateral walking stick & Nil \\
\hline 9 & 17 & Frame & Nil \\
\hline 10 & 17 & 2 crutches & Nil \\
\hline 11 & 25 & Independent & $\mathrm{Nil}$ \\
\hline 12 & 26 & Independent & Nil \\
\hline 13 & 23 & 2 crutches & $\mathrm{Nil}$ \\
\hline 14 & 22 & 2 crutches & $\mathrm{Nil}$ \\
\hline 15 & 23 & 2 crutches & Nil \\
\hline 16 & 30 & Unilateral walking stick & Nil \\
\hline
\end{tabular}

This article is protected by copyright. All rights reserved. 
18

* F/U Month, Follow up from operation date in months

This article is protected by copyright. All rights reserved. 